\title{
The Role of Socio-Cultural and Environmental Risk Factors on The Incidence of Tuberculosis Infection
}

\author{
F. A. Siregar ${ }^{1 *}$ and T. Makmur ${ }^{2}$ \\ ${ }^{I}$ Faculty of Public Health, University of Sumatera Utara, Indonesia \\ ${ }^{2}$ Faculty of Medicine, Islamic University of Sumatera Utara, Indonesia
}

\begin{abstract}
North Sumatera Province is the fourth ranked for tuberculosis in Indonesia and Medan is an endemic district with high morbidity and mortality. Social determinant, lifestyle and environment are contributed to the tuberculosis incidence. The purpose of this study is to determine the influence of social factors, lifestyles and environment against to the tuberculosis incidence in Medan. This is an observational study with unmatching case-control design. The sample consisted of 70 people with pulmonary tuberculosis and 70 people who did not have pulmonary tuberculosis in a ratio of $1: 1$. The sample was selected by purposive sampling based on inclusion criteria. Data were analyzed using simple logistic regression and multiple logistic regression. Of the multiple logistic regression analysis showed that the history of household contact with the patient, alcohol consumption, low nutritional status and housing density are predictor for tuberculosis incidence in Medan with the prediction model of tuberculosis incidence is $-1.394+(2.919 \mathrm{x}$ household contact $)+(1.837 \mathrm{x}$ alcohol consumption $)+(1.802 \mathrm{x}$ low nutritional status $)+(1,117 \mathrm{x}$ housing density $)$. Based on the study results, it is necessary to intensify health promotion and develop an effective strategy in reducing the incidence of tuberculosis.
\end{abstract}

Keywords: Tuberculosis, incidence, sociocultural, environmental risk

\section{Introduction}

Tuberculosis (TB) affects a quarter of the world's population and most of them (75\%) found in developing countries. World Health Organization Tuberculosis Report (2016) noted that Indonesia was the second highest for TB cases among 30 high burden countries worldwide [1]. Furthermore, TB is the number four leading cause of death in Indonesia. Ministry of Health of Indonesia Tuberculosis Report showed that there is an upward trend for TB cases annually [2]. North Sumatera Province is the fifth rank for TB cases with Medan an endemic area with high incidence [3]. The number of TB cases in Medan still high with tend increased annually. Nearly half of them with sputum positive smear and cure rate below the target [4].

Many factors are related to the incidence of tuberculosis. Socio-cultural and environmental factors are play role on the incidence of tuberculosis. Socio-cultural factors includes income, nutritional status, households contact with TB patients, smoking, and alcohol consumption. Environmental factors include housing density, lighting, temperatures and humidity. History of households contact with TB patients positive smear could increase risk of TB transmission. Thereby, increased the number of new TB cases [5,6,7]. Khaliq study et al in Pakistan found people who have low education had 1.29 times the risk for Tuberculosis [6]. Tocque study et al in Liverpool found that people with smoking habit had 2.3 times the risk of developing tuberculosis [8].

Incidence of TB in Medan was high and tend increased. TB control program with the DOTS (Directly Observed Treatment Short course Chemotherapy) strategy had been implemented since 1995 and various efforts had been conducted, however incidence of tuberculosis remains high. In designing an effective prevention and control measures, is necessary to identify risk factors including socio-cultural and environmental factors. Therefore, this study was conducted to provide information in developing an effective TB control strategies. 


\section{Methods}

This study was designed as unmatched case control study and carried out in Medan city from June, 2017 to November, 2017. Medan Helvetia and Medan Marelan were selected purposively as sub district with high and low tuberculosis cases, respectively.

Samples: Cases were patients who diagnosed as tuberculosis patients smear positive and registered as TB patients in health facility. Control were people who without any tuberculosis symptoms who lived close to the residence of TB cases.

Sample size: The sample size was calculated using the two-proportion formula [9], with an average Odds Ratio (OR) of 3. The proportion of exposure in the control group (p0) was 0.20 with an allowable error of $5 \%$ and a power of study of $80 \%$. Therefore, a total of 70 cases and 70 controls were included in this study.

Study Instruments: The socio-cultural data were collected by interview and recorded using questionnaires administered by the researchers. The socio-cultural factors included education, income, and nutritional status, households' contact with TB patients, smoking habits, and alcohol consumption. The environmental data include housing density, temperature, lighting, humidity. For environmental data were collected through measurement environmental parameters such as temperature using thermometer, lighting using lux meter and humidity using hygrometer as well as housing density with compare the number of family member and size of rooms.

Statistical analysis: Data analysis using SPSS Release 22.0 program. Univariate analysis were presented either as frequency distribution and proportion and then were summarized using tables. Simple and multiple logistic regressions were performed to analyze the risk factors were associated with tuberculosis incidence [10].

\section{Results}

A total of 140 samples were included in this study, the sample age was 16 years old and maximum 76 years old with average age was 43,91 years (Table 1). Of the socio-cultural factors, most of respondents came from households with monthly income of less than 2.5 million $(75.7 \%)$, good nutritional status (70\%), no history of households contact $(85,7 \%)$, smoking habits $(47.1 \%)$ and alcohol consumption $(13.6 \%)$ as presented in Table 2.

Table 1. Characteristic of respondent by age

\begin{tabular}{lllll}
\hline Variabel & Minimum & Maximum & Mean & Standard deviasi \\
\hline Umur & 16 & 76 & 43,91 & 15,161 \\
\hline
\end{tabular}

Tablel 2. Socio-cultural factor of respondents

\begin{tabular}{lll}
\hline Variable & frequency & Percentage \\
\hline Income & & \\
$\mathbf{2} \mathbf{2 , 5}$ miliion & 34 & $24,3 \%$ \\
$\quad \mathbf{2 . 5}$ million & 106 & $75,7 \%$ \\
Nutritional & & \\
status & & \\
Good & 98 & $70.0 \%$ \\
Bad & 42 & $30.0 \%$ \\
Households & & \\
\hline
\end{tabular}




\begin{tabular}{lll}
\hline contact & & \\
No & 120 & $85.7 \%$ \\
$\quad$ Yes & 20 & $14.3 \%$ \\
Smoking habits & & \\
$\quad$ No & 74 & $52.9 \%$ \\
$\quad$ Yes & 66 & $47.1 \%$ \\
$\quad$ Alcohol & & \\
consumption & & \\
$\quad$ No & 121 & $86.4 \%$ \\
$\quad$ Yes & 19 & $13.6 \%$ \\
\hline
\end{tabular}

Based on environmental factors, most respondents living in houses with housing density of $\geq 9 \mathrm{~m} 2(55.7 \%)$, humidity of $40-70 \%$ (59.3\%), temperature under health condition (70.7\%) and poorly qualified lighting $(61.4 \%)$ as presented in Table 3 .

Table 3. Environmental characteristics of respondents

\begin{tabular}{|c|c|c|}
\hline Variable & Frequency & Percentage \\
\hline \multicolumn{3}{|l|}{ Housing density } \\
\hline$\geq 9 \mathrm{~m}^{2}$ & 78 & $78(55,7 \%)$ \\
\hline$<9 \mathrm{~m}^{2}$ & 62 & $62(44,3 \%)$ \\
\hline \multicolumn{3}{|l|}{ Humidity } \\
\hline $40-70 \%$ & 83 & $83(59,3 \%)$ \\
\hline$<40 \%$ and $>70 \%$ & $49(40,7 \%)$ & $49(40,7 \%)$ \\
\hline \multicolumn{3}{|l|}{ Temperature } \\
\hline$<31^{\circ} \mathrm{C}$ and $>37^{\circ} \mathrm{C}$ & $41(29,3 \%)$ & $41(29,3 \%)$ \\
\hline $31-37^{\circ} \mathrm{C}$ & $99(70.7 \%)$ & $99(70.7 \%)$ \\
\hline \multicolumn{3}{|l|}{ Lighting } \\
\hline$\geq 60$ lux & $54(38,6 \%)$ & $38.6 \%$ \\
\hline$<60$ lux & $86(61,4 \%)$ & $61.44 \%$ \\
\hline
\end{tabular}

Of the simple logistic regression showed that income, nutritional status, households contact with TB patients, smoking habits, alcohol consumption and housing density were significant factors for tuberculosis infection that indicated with $\mathrm{p}$ values less than 0.25 ( Table 4). Then these variables were included in multiple logistic regression and with Enter methods revealed that only four variables were significant for tuberculosis incidence such as households contact with TB patients, alcohol consumption, low nutritional status and housing density as presented in Table 5. Then four these variables put into the fit model through using Hosmer lemeshow, classification table and ROC curve. The results show that model fit with Hosmer lemeshow 0.898 ; clasification table $76.4 \%$ and also ROC curve $81.8 \%$ as presented in Figure 1. 


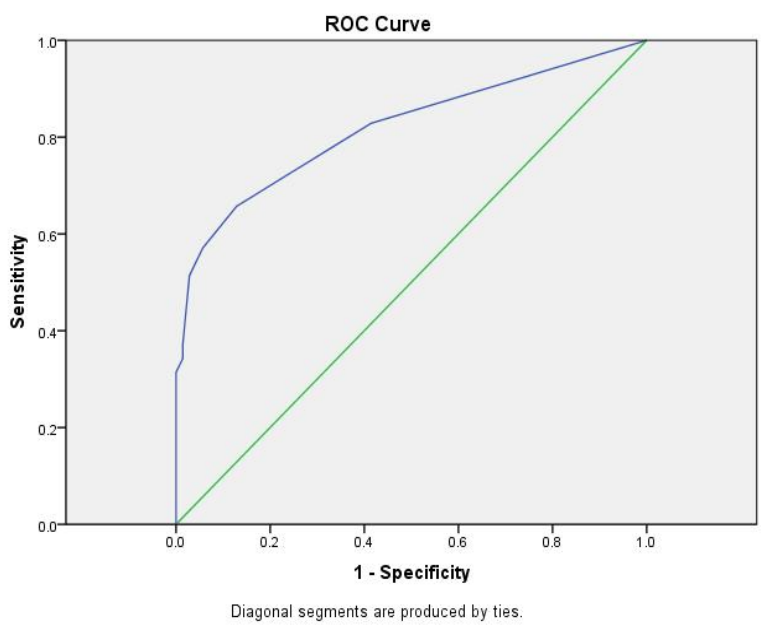

Figure1. Area under the ROC Curve

Therefore, it was assumed that $81.8 \%$ of tuberculosis incidence can be explained by risk factors such as households contact with TB patients, alcohol consumption, low nutritional status and housing density with the equation for prediction model tuberculosis incidence is $-1.394+(2.919 \mathrm{x}$ household contact $)+(.837 \mathrm{x}$ alcohol consumption $)+(1.802 \mathrm{x}$ low nutritional status $)+(1.117 \mathrm{x}$ housing density $)$.

Table 4. Factors associated with tuberculosis infection using Simple Logistic

\begin{tabular}{|c|c|c|c|c|}
\hline Variable & Cases (\%) & Control (\%) & $\begin{array}{l}\text { Crude OR } \\
(95 \% \text { CI })\end{array}$ & $\begin{array}{l}p \\
\text { value }\end{array}$ \\
\hline \multicolumn{5}{|l|}{ Income } \\
\hline$\geq 2,5$ juta & $12(7.1 \%)$ & $22(31.4 \%)$ & 1.833 & \multirow[t]{2}{*}{0.124} \\
\hline$<2,5$ juta & $58(82.9 \%)$ & $48(68.6 \%)$ & $(0.846 ; 3.972)$ & \\
\hline \multicolumn{5}{|c|}{$\begin{array}{l}\text { Nutritional } \\
\text { status }\end{array}$} \\
\hline Good & $37(52.8 \%)$ & $64(91.4 \%)$ & 9.000 & \multirow[t]{2}{*}{0.000} \\
\hline Bad & $33(47.2 \%)$ & $7(8.6 \%)$ & $(3.620 ; 22.373)$ & \\
\hline \multicolumn{5}{|c|}{$\begin{array}{l}\text { Households } \\
\text { contacts }\end{array}$} \\
\hline No & $51(72.9 \%)$ & $69(98.6 \%)$ & 25.076 & \multirow[t]{2}{*}{0.002} \\
\hline Yes & $19(27.1 \%)$ & $1(1.4 \%)$ & $(3.332 ; 198.326)$ & \\
\hline \multicolumn{5}{|c|}{ Smoking habits } \\
\hline No & $33(47.1 \%)$ & $41(58.6 \%)$ & 1.585 & \multirow[t]{2}{*}{0.177} \\
\hline Yes & $37(52.9 \%)$ & $29(41.4 \%)$ & $(0.813 ; 3.092)$ & \\
\hline \multicolumn{5}{|c|}{$\begin{array}{l}\text { Alcohol } \\
\text { consumption }\end{array}$} \\
\hline No & $53(75.7 \%)$ & $68(97.1 \%)$ & 10.906 & \multirow[t]{2}{*}{0.002} \\
\hline Yes & $17(24.3 \%)$ & $2(2.9 \%)$ & $(2.413 ; 49.295)$ & \\
\hline \multicolumn{5}{|c|}{ Housing density } \\
\hline$\geq 9 \mathrm{~m} 2$ & $29(41,4 \%)$ & $49(70 \%)$ & 3,299 & \multirow[t]{2}{*}{0,001} \\
\hline$<9 \mathrm{~m} 2$ & $41(8,6 \%)$ & $21(30 \%)$ & $(1,641 ; 6,631)$ & \\
\hline
\end{tabular}




\begin{tabular}{lllll}
\hline $\begin{array}{l}\text { Humidity } \\
\mathbf{4 0 - 7 0 \%}\end{array}$ & $41(58,6 \%)$ & $42(60 \%)$ & 1,061 & 0,863 \\
$<\mathbf{4 0 \%} \%$ and $>\mathbf{7 0 \%}$ & $29(41,4 \%)$ & $20(40 \%)$ & $(0,541 ; 2,083)$ & \\
$\begin{array}{l}\text { Temperature } \\
\text { <310C and }>\end{array}$ & $20(28,6 \%)$ & $21(30 \%)$ & 1.071 & 0,853 \\
370C & $50(71,4 \%)$ & $49(70 \%)$ & $(0,517 ; 2,219)$ & \\
31-37 0C & & & & \\
Lighting & & & & 0,728 \\
$\geq \mathbf{6 0}$ lux & $26(37,1 \%)$ & $28(40 \%)$ & 1,128 & \\
$<\mathbf{6 0}$ lux & $44(62,9 \%)$ & $42(70 \%)$ & $(0,571 ; 2,229)$ & \\
\hline
\end{tabular}

\section{Discussion}

History of contact with a smear positive tuberculosis patient is a risk factor for tuberculosis incidence. Proximity factor and frequency of contact is important. Frequent contact with TB patients with smear positive will facilitate exposure to healthy people and eventually become susceptible to infection. In this study proportion of cases had households contact with TB patients was $27.1 \%$, which means greater than in the control group which was only $1.4 \%$. Statistically, of the multiple regression analysis showed $p=0.001$ and $\mathrm{OR}=47.5$. This findings was similar to Singh (2005) found that prevalence of tuberculosis infection was higher ( 3.2 times ) in population with households contact with TB patients compare to general population who have no households contact [11].

People with positive smear tuberculosis can transmit to 10-15 people. One cough sufferer can produce about 3000 sputum sputum (droplet) that contain germs can infect the environment. Droplet with a larger size will fall to the ground, however smaller ones will hover on air [12] and in a long time, it could be inhaled through human breathing.

Table 5. Factors associated with tuberculosis infection using Multiple Logistic

\begin{tabular}{llll}
$\begin{array}{l}\text { Regression } \\
\text { Variable }\end{array}$ & $\begin{array}{l}\text { Crude OR } \\
(\mathbf{9 5 \%} \mathbf{C I})\end{array}$ & Adjusted OR & p value \\
\hline $\begin{array}{l}\text { Nutritional } \\
\text { status } \\
\text { Good }\end{array}$ & 9.000 & & \\
$\quad$ Bad & $(3.620 ; 22.373)$ & $(2.22 ; 16.58)$ & \\
$\begin{array}{l}\text { Households } \\
\text { contacts }\end{array}$ & & & \\
$\quad$ No & 25.076 & 18.52 & 0.000 \\
$\quad$ Yes & $(3.332 ; 198.326)$ & $(2.19 ; 156.25)$ & \\
$\begin{array}{l}\text { Alcohol } \\
\text { consumption }\end{array}$ & & & \\
$\quad$ No & & & \\
$\quad$ Yes & 10.906 & 6.27 & 0.033 \\
Housing density & $(2.413 ; 49.295)$ & $(1.16 ; 34.01)$ & \\
$\geq \mathbf{9}$ m2 & 3,299 & & \\
$\quad<9$ m2 & $(1,641 ; 6,631)$ & $(1.33 ; 7.01)$ & 0,008 \\
\hline
\end{tabular}

Enter Multiple Logistic Regression was applied. Multicolinearity were checked and not found.The interaction was found. Hosmer Lemeshow test ( $\mathrm{p}=0.898)$. Classification table ( 
overall correctly classified percentage $=76.4$. Area under the ROC curve $(81.8 \%)$ were applied to check the model fitness

Malnutrition in TB infection decreases immune status due to decreased lymphocyte production and immune cell proliferation ability that impact on the increased growth of microorganisms and infection risk. In this study $47.2 \%$ of tuberculosis cases had low nutritional status, while in the control group only $8.2 \%$ had low nutritional status. Of the Multiple regression analysis found that people who have low nutritional status at risk of tuberculosis 6.08 times greater than those who do not have low nutritional status. This finding was consistent to Sing's study (2005) in India found that people with malnutrition have a risk of tuberculosis infection 3.97 times greater than those without malnutrition.

Several studies showed that there was a relationship between alcohol use and the risk of tuberculosis. Alcohol may impact a direct toxic effects on the immune system and cause host more susceptible to TB disease. It also may be through inhibited tumor necrosis factor (TNF) response and could reduce system response that prevent destruction of mycrobacteria. In this study $24.3 \%$ of tuberculosis cases had alcohol consumption, while in the control group only $2.9 \%$ had alcohol consumption. Of the multiple logistic regression found people who had alcohol consumption at risk 6.27 times to tuberculosis than people who had no alcohol consumption. This findings was consistent to Lönnroth et al found that people who drink alcohol consumption have a risk at 2.94 to tuberculosis infection than people who did not alcohol consumption. They concluded that risk of tuberculosis was increased among people who drink more than $40 \mathrm{~g}$ alcohol per day [13].

Housing density is the potential risk factor to increase the probability of tuberculosis transmission. This is related to exposure of susceptible people to people who had infectious pulmonary disease. The association between housing density and tuberculosis incidence had been studied and found that the incidence of tuberculosis was higher in communities with higher housing density [12]. In this study $41.4 \%$ of tuberculosis cases live in high housing density, and $27.1 \%$ of them have history households contact. Of the Multiple regression analysis found that people who live in crowded housing density have a risk of tuberculosis 3.29 times greater than those people who did not live in crowded housing density. This findings was consistent to Baker study et al in New Zealand found that households crowding was associated with tuberculosis incidence in New Zealand [14]. Likewise Tornee et al (2004) in Thailand found that people who live in crowded households have a risk of tuberculosis 2.63 times than people who did not live in a crowded households [15].

\section{Conclusion}

Our study revealed that socio-cultural and environmental risk factors are associated with tuberculosis infection. Households contact, alcohol consumption, low nutritional status and crowded housing density are predictor for tuberculosis infection. Therefore, it is necessary to intensify health promotion to improve preventive measures and develop an effective strategy in tuberculosis program to reduce new cases.

\section{Conflict of Interest}

No conflict interest involved in this study.

\section{Source of Funding}

This study was funded by Rector University of Sumatera Utara through TALENTA Grant.

\section{Ethical Clearance}

Before the study was conducted, human subject approval was obtained from The University of North Sumatera on July, 6 2017. The study was approved by the Research and Ethics Committee, School of Nursing, University of North Sumatera (Reference code number 1243/VII/SP /2017). 


\section{Acknowledgement}

We are thankful to Rector University of Sumatera Utara provide financial support for this research. Thanks also for head of district health office and head of health facility for their assistance and for all people who were involved in this study.

\section{References}

[1].World Health Organization (WHO). Global Tuberculosis Report 2017.

http://www.who.int/tb/publications/global_report/en/.

[2].World Health Organization (WHO).2016. Global Tuberculosis Report 2015.

http://www.who.int/tb/publications/global_report/en/.

[3]. Ministry of Health of Indonesia. 2016. Indonesian Health Profile. Jakarta 2016.

[4]. Medan District Health Office (2015). Tuberculosis case report in Medan

[5]. Sun, W. Gong, J., Zhou, J., Zhao, Y., Tan, J., Ibrahim, A., \& Zhou, Y. (2015). A Spatial, Social and Environmental Study of Tuberculosis in China Using Statistical and GIS Technology. International Journal of Environmental Research and Public Health, 12(2), 1425-1448.

[6]. Khaliq, A. Khan, I.A. Akhtar MW, Chaudhry M.N, Environmental risk factors and social determinant of Pulmonary Tuberculosis in Pakistan. Epidemiology (Sunnyvale), 5(3), 1-9.

[7]. Leung, C.C. Chang,K.C. (2008). Impact of lifestyle on Tuberculosis. Respirology. 13(3) S63-S72.

[8]. Tocque, K, Bellis, M..A, Beeching N.J, Syed Q, Remmington, T, Davies, P.D. (2001). A Case control study of lifestyle risk factors associated with tuberculosis in Liverpool, North West England. European Respiratory Journal.2001.18: 959-964.

[9]. Naing, N. N. (2010). A practical guide on determination on sample size in health science research.Malaysia: Pustaka Aman Press, p 36-57.

[10].Norsa'adah, B. (2011). Multivariate analysis regression. Malaysia: Kota Bharu, p 38-67

[11 Singh, M., Mynak, M. L., Kumar, L., Mathew, J. L., \& Jindal, S. K. (2005). Prevalence and risk factors for transmission of infection among children in household contact with adults having pulmonary tuberculosis. Archives of disease in childhood, 90(6), 624-628.

[12]. Crofton, J., Horne, N.; Miller, F. 2002. Clinical Tuberculosis. Jakarta: Widya Medika

[13]. Lönnroth, K., Williams, B. G., Stadlin, S., Jaramillo, E., \& Dye, C. (2008). Alcohol use as a risk factor for tuberculosis-a systematic review. BMC public health, 8(1), 289.

[14].Baker, M., Das, D., Venugopal, K., \& Howden-Chapman, P. (2008). Tuberculosis associated with household crowding in a developed country. Journal of Epidemiology \& Community Health, 62(8), 715721.

[15].Tornee, S., Kaewkungwal, J., Fungladda, W., Silachamroon, U., Akarasewi, P., \& Sunakorn, P. (2004). Risk factors for tuberculosis infection among household contacts in Bangkok, Thailand. Southeast Asian Journal of Tropical Medicine \& Public Health, 35(2), 375-383. 